\title{
Removal of Endotracheal Tube Obstruction With a Secretion Clearance Device
}

\author{
Cristina Mietto MD, Kevin Foley RRT, Lindsay Salerno RRT, Jenna Oleksak RRT, \\ Riccardo Pinciroli MD, Jeremy Goverman MD, and Lorenzo Berra MD
}

\begin{abstract}
Accumulation of secretions may suddenly occlude an endotracheal tube (ETT), requiring immediate medical attention. The endOclear catheter (Endoclear LLC, Petoskey, Michigan) is a novel device designed to clear mucus and debris from an ETT and restore luminal patency. We present 3 subsequent cases of life-threatening partial ETT occlusions recorded over a period of 6 months at Massachusetts General Hospital. After conventional methods (standard tracheal suctioning and bronchoscopy) failed, the endOclear was used, with successful restoration of the airways in all 3 cases. The respiratory conditions rapidly improved, and all 3 patients tolerated the ETT-cleaning maneuver. These results show that such a device is safe and easy to use during an emergency airway situation for efficient and rapid removal of secretions from obstructed ETTs by respiratory therapists. Key words: respiration; artificial; positive-pressure ventilation; respiratory failure; airway obstruction; airway resistance; pneumonia; ventilator-associated; biofilms. [Respir Care 2014;59(9):e122-e126. @ 2014 Daedalus Enterprises]
\end{abstract}

\section{Introduction}

Patency of an endotracheal tube (ETT) during mechanical ventilation is often compromised by the accumulation of luminal debris. A flexible catheter is generally used to remove these secretions by suctioning, a maneuver that can be performed either in a closed or open fashion according to local clinical practice. ${ }^{1}$ Nevertheless, evidence

\footnotetext{
Drs Mietto, Pinciroli, and Berra are affiliated with the Department of Anesthesia, Critical Care and Pain Medicine; Mr Foley, Ms Salerno, and Ms Oleksak are affiliated with the Department of Respiratory Care; and Dr Goverman is affiliated with the Department of Surgery, Burn Service, Massachusetts General Hospital, Boston, Massachusetts.
}

\footnotetext{
This work was supported by the Department of Anesthesia, Critical Care and Pain Medicine and the Department of Respiratory Care, Massachusetts General Hospital, Boston, Massachusetts. Endoclear LLC provided equipment to Massachusetts General Hospital for 6 months for clinical trial (free of cost) from April to September 2013. The authors have disclosed no conflicts of interest.
}

Correspondence: Lorenzo Berra MD, Department of Anesthesia, Critical Care and Pain Medicine, Massachusetts General Hospital, White 434-B, 55 Fruit Street, Boston, MA 02114. E-mail: lberra@partners.org.

DOI: $10.4187 /$ respcare.02995 suggests that, even if periodically repeated during mechanical ventilation, standard suctioning is not sufficient to preserve the ETT's original lumen size and nominal function. ${ }^{2}$ Abrupt occlusion is rare but can be life-threatening, potentially requiring emergency airway restoration. ETT exchange may be required to ventilate and oxygenate the patient, a high-risk procedure in an emergency ICU setting. ${ }^{3}$ In contrast, partial occlusion due to secretion accumulation is ubiquitous and recklessly ignored, with an average estimated loss of intraluminal ETT volume of between 9 and 15\%.4,5 Occlusion increases the air-flow resistance within the ETT, thereby imposing additional work of breathing on critically ill patients. ${ }^{6,7}$ Moreover, pathogen-laden secretions stationed within the tube may migrate and colonize the lower respiratory tract, causing pneumonia. ${ }^{8,9}$

Thus, the theoretical benefits of preserving the ETT's original function include (1) reducing the likelihood of sudden hazardous ETT occlusions and the subsequent need for emergency interventions; (2) decreasing airway resistance and work of breathing in intubated critically ill patients, eventually facilitating their weaning process, which might ultimately lead to reduced mechanical ventilation time; and (3) reducing the incidence of ventilatorassociated events by preventing pathogens from forming bacterial biofilm within the ETT. 


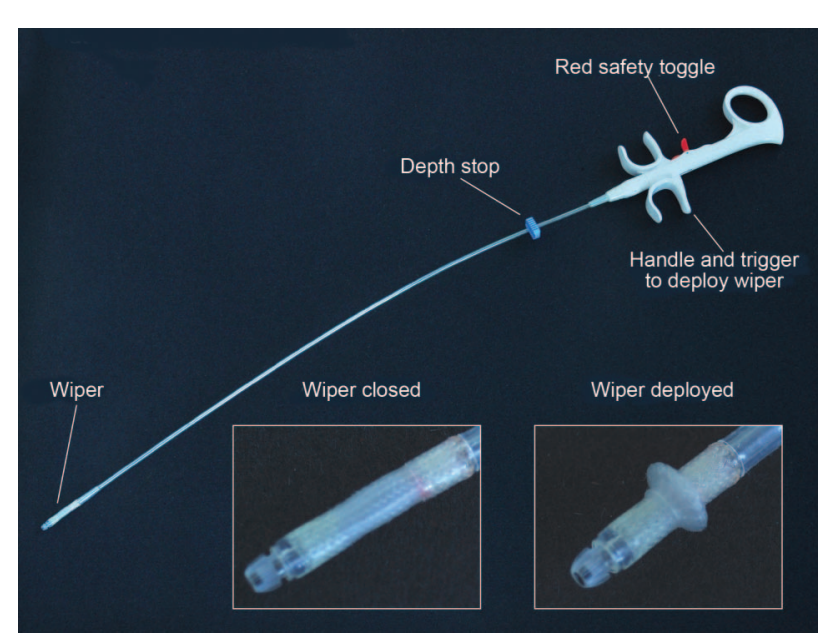

Fig. 1. The endOclear endotracheal tube-cleaning device. Courtesy Endoclear LLC.

Since April 2013, the endOclear catheter (Endoclear LLC, Petoskey, Michigan) has been used in the Respiratory Care Department of Massachusetts General Hospital (Boston, Massachusetts) to clear secretions from ETT lumina (Fig. 1). It is a novel medical device designed to clean the ETT without an interruption in mechanical ventilation. The endOclear consists of a flexible central tube and a smooth disc-shaped wiper at its distal end.

The device is inserted into an ETT through a dedicated adapter until it touches the adjustable blue safety stop (see Fig. 1), preventing overinsertion. The patient continues to be mechanically ventilated throughout the procedure due to the Y-shape of the adapter. The red safety toggle is then disengaged to allow subsequent active deployment of the distal end of the device. Firmly grasping the handle, the trigger is fired to deploy and expand the smooth wiper end. When activated, the distal cleaning apparatus shifts from a closed to an open position. Once deployed, the wiper can firmly engage the inside walls of the ETT. The endOclear is then pulled out of the ETT, thereby removing secretions and biofilm from inside the lumen. Overall, the process of insertion, activation, and clearing of the ETT (distal to proximal end) requires 3-5 s. Collected secretions are trapped inside a side port of the device connector (not shown in Fig. 1), and the whole system can then be discarded.

We present 3 subsequent life-threatening cases recorded over 6 months in which the device was used by staff respiratory therapists to emergently resume mechanical ventilation after standard ETT-cleaning methods had failed.

\section{Case 1: Medical ICU}

An obese 60-y-old woman was admitted to the medical ICU at our institution from an outside hospital for management of severe ARDS due to Legionella pneumophila

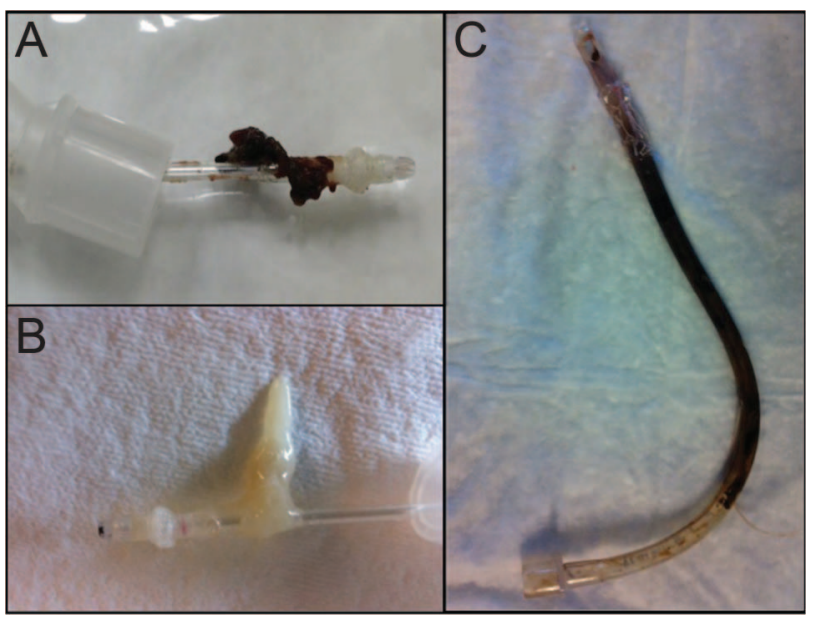

Fig. 2. A: Tip of the endOclear device with dried secretions after endotracheal tube (ETT) cleaning (case 1). B: Tip of the endOclear device with a large mucus plug after ETT cleaning (case 2). C: An occluded ETT from a ICU burn patient (case not presented). Standard suctioning and emergency bronchoscopy did not maintain normal gas exchange and ventilation. The patient had to be reintubated to resume oxygenation and ventilation.

pneumonia. The patient was already sedated and intubated with a $7.5-\mathrm{mm}$ internal diameter ETT. Chest x-ray showed diffuse opacification in the right lung and patchy opacification in the left mid and lower lung, consistent with pneumonia. Humidification of the airways was provided by a dual heated-wire circuit (ConchaTherm Neptune, Teleflex Medical, Research Triangle Park, North Carolina). Upon arrival, the ventilator settings were volume controlled ventilation at 14 breaths $/ \mathrm{min}$, tidal volume of $6 \mathrm{~mL} / \mathrm{kg}$ of ideal body weight, PEEP of $18 \mathrm{~cm} \mathrm{H}_{2} \mathrm{O}$, and $\mathrm{F}_{\mathrm{IO}_{2}}$ of 0.80 $\left(\mathrm{P}_{\mathrm{aO}_{2}} / \mathrm{F}_{\mathrm{IO}_{2}}=90\right)$. During the night, the respiratory therapist noted that the patient was not synchronous with the ventilator due to double triggering from abdominal rebound. Moreover, the peak pressure was progressively increasing at the same ventilator setting. Once switched to pressure controlled ventilation, the tidal volume was remarkably reduced, and the ventilator autotriggered repeatedly. Members of the ICU team attempted standard closed-system suctioning (closed suction system No. 14, Kimberly-Clark, Neenah, Wisconsin) but were unable to pass the catheter through the ETT lumen. After instillation of saline and multiple attempts to lavage the ETT to help break up the occlusion, only minimal secretions were retrieved. As ventilation was increasingly difficult, the patient was disconnected from the ventilator, and manual bag ventilation was initiated, saline was instilled, and suctioning was attempted again, pulling out some dark-colored secretions. At that point, the endOclear was inserted, and a large, dark, dry mucus plug was retrieved (Fig. 2A). Patient-ventilator synchrony was restored, and ventilation was immediately resumed. 
The respiratory therapist's rapid recognition of the situation, combined with the prompt resolution of the ETT occlusion by the endOclear, prevented a hazardous reintubation in this hypoxic patient with severe ARDS and high-pressure ventilator settings.

\section{Case 2: Medical ICU}

An adult male patient with a history of multiple hospitalizations for bronchiectasis was admitted to the medical ICU with pneumonia. The patient was intubated with an 8.0-mm internal diameter ETT, mechanically ventilated for several days for respiratory failure, and treated with appropriate antibiotics. Readiness for extubation was assessed daily with a spontaneous breathing trial (PEEP of $2 \mathrm{~cm} \mathrm{H}_{2} \mathrm{O}$, pressure support of $0 \mathrm{~cm} \mathrm{H}_{2} \mathrm{O}, \mathrm{F}_{\mathrm{IO}_{2}}$ of 0.40 ). On day 8 of mechanical ventilation, the respiratory therapist found the patient in distress during his trial secondary to high breathing frequency within minutes of starting the trial. On examination, the patient was using accessory muscles; on auscultation, he had diminished breath sounds bilaterally. Oxygen saturation decreased from $100 \%$ to $\sim 90 \%$. Figure $3 \mathrm{~A}$ is an image of the ventilator screen showing early changes in the pressure/flow curves due to secretion accumulation in the ETT. After standard suctioning of the ETT, the patient became more agitated, and marginal secretions were retrieved from the ETT lumen. The respiratory therapist decided to try the endOclear tube scraper and was able to remove a large amount of secretions (see Fig. 2B). Within a few minutes, the patient's breathing frequency slowed to $\sim 20$ breaths/min, the breathing pattern improved, oxygen saturation increased to nearly $100 \%$, and normal pressure/flow curves were recorded on the ventilator (Fig. 3). The spontaneous breathing trial was resumed, and the patient successfully passed the trial within the hour and was extubated later in the day. The intervention of the respiratory therapist enabled this patient to be weaned from prolonged mechanical ventilation by passing his breathing trial with sameday successful extubation, avoiding extra ventilator days and a possible tracheostomy.

\section{Case 3: Surgical ICU}

A 70-y-old male with a significant past medical history of COPD and a 100-pack-year smoking history was admitted to our institution from an outside hospital for management of severe hypernatremia, a right exudative pleural effusion of uncertain etiology, and respiratory failure due to right middle and lower lobe pneumonia. The patient was intubated with a 7.5-mm internal diameter ETT and transferred to the surgical ICU after insertion of a chest tube for a right pleural effusion and bronchoscopy showing thick secretions. The patient was diagnosed with stage 4 angio-
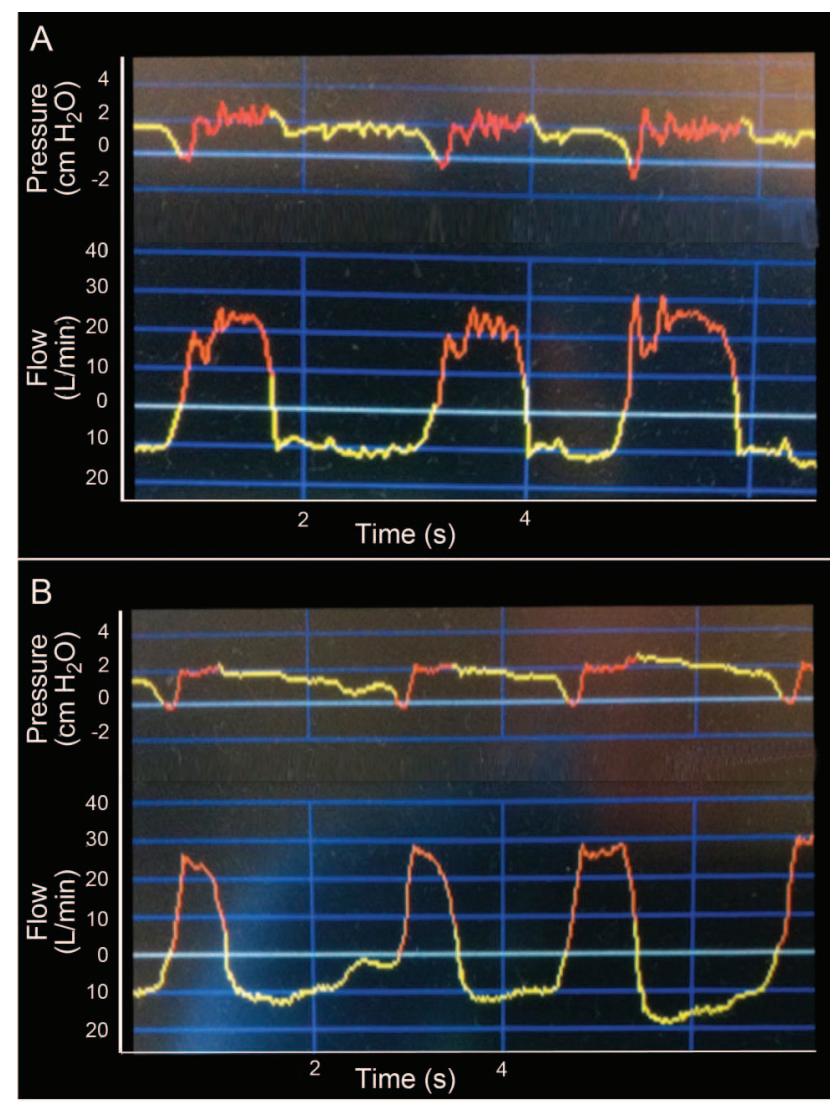

Fig. 3. Pressure/flow curves on the ventilator before and after use of the endOclear. A: The patient is failing his spontaneous breathing trial. B: Note the early changes in the pressure/flow curves that were restored to normal baseline after endOclear use.

immunoblastic $\mathrm{T}$ cell lymphoma and hemolytic anemia. His ICU stay was complicated by bone marrow suppression, acute kidney injury, and Enterobacter species pneumonia requiring prolonged ventilation.

Mechanical ventilation was changed accordingly during the ICU course. Humidification was provided via ConchaTherm Neptune, and a dual heated-wire circuit was used. On day 14 , the ventilator settings were volume controlled ventilation at 18 breaths/min, tidal volume of $400 \mathrm{~mL}$ ( $7 \mathrm{~mL} / \mathrm{kg}$ of ideal body weight), PEEP of $5 \mathrm{~cm} \mathrm{H}_{2} \mathrm{O}$, and $\mathrm{F}_{\mathrm{IO}_{2}}$ of 0.40 . Early in the day, the peak pressure increased from $\sim 20 \mathrm{~cm} \mathrm{H}_{2} \mathrm{O}$ to $25-30 \mathrm{~cm} \mathrm{H}_{2} \mathrm{O}$.

Vital signs were stable until the respiratory therapist noticed an acute airway obstruction and called the anesthesiologist to the bedside after trying to advance a suction catheter through a 7.5-mm ETT without success. Peak inspiratory pressure was $\sim 50 \mathrm{~cm} \mathrm{H}_{2} \mathrm{O}$, and minute volume dropped to $<1 \mathrm{~L} / \mathrm{min}$. Auscultation revealed louder breath sounds on the left than the right. A mucus plug was suspected, and an anesthesiologist performed emergency bronchoscopy, which revealed copious thick tenacious yellow mucus lining the entire ETT. Interestingly, all of the air- 
Table 1. Nonstandard Catheters That Effectively Clean Secretions From Within the ETT

\begin{tabular}{|c|c|c|}
\hline Reference & Device & Findings \\
\hline Berra et al ${ }^{12}$ & Mucus Shaver & $\begin{array}{l}\text { The device was tested in } 12 \text { patients ventilated for }>72 \mathrm{~h} \text { and } \\
\text { shown to be a safe and effective device for ETT cleaning. }\end{array}$ \\
\hline Conti et al ${ }^{13}$ & Obstruction Remover & $\begin{array}{l}\text { This device was used in } 8 \text { consecutive, unselected, } \\
\text { mechanically ventilated, critically ill patients in which a } \\
\text { partial ETT obstruction was suspected. The authors found } \\
\text { that their device could be safely and successfully used to } \\
\text { remove obstructions from the ETT lumen without } \\
\text { suspending mechanical ventilation, reducing the need for } \\
\text { rapid ETT substitution in emergency and life-threatening } \\
\text { situations. }\end{array}$ \\
\hline Li Bassi et al ${ }^{14}$ & Mucus Slurper & $\begin{array}{l}\text { No clinical trials have been carried out on the use of this } \\
\text { device. A laboratory study of the device showed that it is } \\
\text { able to prevent accumulation of secretions in sheep } \\
\text { ventilated for } 72 \mathrm{~h} \text {. }\end{array}$ \\
\hline Currently under experimentation & Airway Medix & \\
\hline This report & endOclear & $\begin{array}{l}\text { The present report showed safety and efficacy in removing } \\
\text { ETT occlusions. }\end{array}$ \\
\hline Stone and Bricknell ${ }^{15}$ & Rescue Cath & $\begin{array}{l}\text { The authors provided a case report series in which a catheter } \\
\text { was used to successfully remove secretions in } 3 \text { obstructed } \\
\text { ETTs. }\end{array}$ \\
\hline Liu et al ${ }^{16}$ & Sterile urethral catheters & $\begin{array}{l}45 \text { children were randomized to standard of care or to ETT } \\
\text { cleaning with a urethral catheter every } 8 \text { or } 12 \mathrm{~h} \text {. } \\
\text { Mechanical cleaning demonstrated efficacy in reducing } \\
\text { bacterial colonization and preventing biofilm formation. }\end{array}$ \\
\hline
\end{tabular}

ETT $=$ endotracheal tube

ways below the ETT were clear. After bronchoscopy, the ICU team was unable to reduce peak pressure and resume ventilation. The team considered re-intubation with a new ETT, but the respiratory therapist suggested using the endOclear to pull out the rest of the mucus. After the first pass, a large mucus plug ( $\sim 4 \mathrm{~mL}$ of thick secretions) was retrieved, and the obstruction was cleared. Bronchoscopy confirmed the patency and clearance of the ETT lumen. The peak airway pressure returned to $\sim 20 \mathrm{~cm} \mathrm{H}_{2} \mathrm{O}$. An unnecessary re-intubation and prolonged bronchoscopy to retrieve secretions from the ETT were avoided by cleaning the ETT with the endOclear.

\section{Discussion}

We reported 3 cases at our institution over a period of 6 months in which the endOclear catheter was used effectively to remove ETT occlusions when standard methods failed. During this time, a total of 1,792 patients were admitted to ICUs at our institution. Eight-hundred patients were ventilated for $>48 \mathrm{~h}$, equal to 133 patients/month.

In all cases, the use of the device was associated with a rapid improvement of the clinical condition of the critically ill patients, avoiding risky and otherwise inevitable re-intubation. Despite the rapid deterioration of the patients' conditions, the maneuvers were effective and safely accomplished in all cases by the respiratory therapists in collaboration with the ICU team.

Although better humidification has decreased acute ETT occlusion events, the need to change ETTs in ICU patients due to an inability to clear secretions from the ETT lumen is not rare. Indeed, just before adopting the endOclear, the common practice at our institution was to immediately exchange the ETT if emergency bronchoscopy did not restore adequate air flow through the ETT lumen (see Fig. 2C).

Moreover, the literature shows that partial ETT obstruction is a universal problem in intubated and mechanically ventilated patients. ${ }^{2,4-7}$ Standard ETT-cleaning methods have failed to show optimal ETT integrity, and debris always accumulates along the entire length of an ETT. ${ }^{10}$ ETT-cleaning devices specifically aim to remove secretions attached to the ETT, acting like a wiper on the internal surface of the tube. ${ }^{11}$ Table 1 summarizes some of the non-standard catheters that effectively clear secretions from within the ETT; however, none of these devices have been systematically tested in large clinical trials to determine clinical benefits and improved outcomes. The Mucus Shaver has been shown to be safe in a clinical setting and to effectively remove ETT mucus deposits. ${ }^{12}$

On the basis of these observations, we designed a randomized control trial at Massachusetts General Hospital 


\section{Removal of ETt Obstruction With a Secretion Clearance Device}

to evaluate the efficacy of the endOclear compared with standard suctioning alone to maintain ETT lumen patency in patients requiring prolonged mechanical ventilation (ClinicalTrials.gov registration NCT01765530). ${ }^{17}$

The reported case series showed the effectiveness of a device such as the endOclear to remove secretions in complete ETT obstructions. A randomized control trial will enable us to understand whether such a device should be used for all patients who are ventilated for $>48 \mathrm{~h}$.

\section{REFERENCES}

1. American Association for Respiratory Care. AARC Clinical Practice Guidelines. Endotracheal suctioning of mechanically ventilated patients with artificial airways 2010. Respir Care 2010;55(6):758-764.

2. Glass C, Grap MJ, Sessler CN. Endotracheal tube narrowing after closed-system suctioning: prevalence and risk factors. Am J Crit Care 1999;8(2):93-100.

3. Nolan JP, Kelly FE. Airway challenges in critical care. Anaesthesia 2011;66(Suppl 2):81-92.

4. Boqué MC, Gualis B, Sandiumenge A, Rello J. Endotracheal tube intraluminal diameter narrowing after mechanical ventilation: use of acoustic reflectometry. Intensive Care Med 2004;30(12):2204-2209.

5. Shah C, Kollef MH. Endotracheal tube intraluminal volume loss among mechanically ventilated patients. Crit Care Med 2004;32(1): 120-125.

6. Heyer L, Louis B, Isabey D, Lofaso F, Brochard L, Fredberg JJ, Harf A. Noninvasive estimate of work of breathing due to the endotracheal tube. Anesthesiology 1996;85(6):1324-1333.

7. Villafane MC, Cinnella G, Lofaso F, Isabey D, Harf A, Lemaire F, Brochard L. Gradual reduction of endotracheal tube diameter during mechanical ventilation via different humidification devices. Anesthesiology 1996;85(6):1341-1349.
8. Adair CG, Gorman SP, Feron BM, Byers LM, Jones DS, Goldsmith $\mathrm{CE}$, et al. Implications of endotracheal tube biofilm for ventilatorassociated pneumonia. Intensive Care Med 1999;25(10):1072-1076.

9. Gil-Perotin S, Ramirez P, Marti V, Sahuquillo JM, Gonzalez E, Calleja I, et al. Implications of endotracheal tube biofilm in ventilatorassociated pneumonia response: a state of concept. Crit Care 2012; 16(3):R93.

10. Pinciroli R, Mietto C, Berra L. Use of high-definition computed tomography to assess endotracheal tube luminal narrowing after mechanical ventilation. Anesthesiology 2013;119(1):202.

11. Kolobow T, Berra L, Li Bassi G, Curto F. Novel system for complete removal of secretions within the endotracheal tube. The Mucus Shaver. Anesthesiology 2005;102(5):1063-1065.

12. Berra L, Coppadoro A, Bittner EA, Kolobow T, Laquerriere P, Pohlmann JR, et al. A clinical assessment of the Mucus Shaver: a device to keep the endotracheal tube free from secretions. Crit Care Med 2012;40(1):119-124.

13. Conti G, Rocco M, De Blasi RA, Lappa A, Antonelli M, Bufi M, Gasparetto A. A new device to remove obstruction from endotracheal tubes during mechanical ventilation in critically ill patients. Intensive Care Med 1994;20(8):573-576.

14. Li Bassi G, Curto F, Zanella A, Stylianou M, Kolobow T. A 72-hour study to test the efficacy and safety of the "Mucus Slurper" in mechanically ventilated sheep. Crit Care Med 2007;35(3):906-911.

15. Stone RH, Bricknell SS. Experience with a new device for clearing mucus from the endotracheal tube. Respir Care 2011;56(4):520-522.

16. Liu W, Zuo Z, Ma R, Zhang X. Effect of mechanical cleaning of endotracheal tubes with sterile urethral catheters to reduce biofilm formation in ventilator patients. Pediatr Crit Care Med 2013;14(7): e338-343.

17. Kacmarek RM. Efficacy study of a novel device to clean the endotracheal tube. NCT01765530. Updated January 2014. http://clinical trials.gov/show/NCT01765530. Accessed July 3, 2014. 